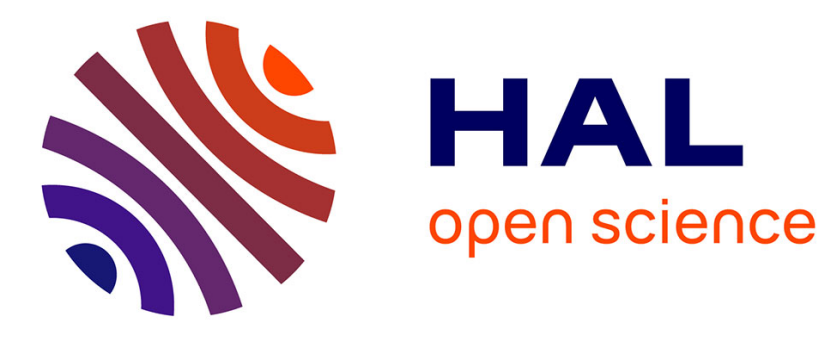

\title{
Diode lasers for material processing
}

\author{
H. Tönshoff, A. Berndt, M. Stürmer, D. Golla, J. Schumacher
}

\section{To cite this version:}

H. Tönshoff, A. Berndt, M. Stürmer, D. Golla, J. Schumacher. Diode lasers for material processing. Journal de Physique IV Proceedings, 1994, 04 (C4), pp.C4-59-C4-63. 10.1051/jp4:1994411 . jpa00252559

\section{HAL Id: jpa-00252559 https://hal.science/jpa-00252559}

Submitted on 1 Jan 1994

HAL is a multi-disciplinary open access archive for the deposit and dissemination of scientific research documents, whether they are published or not. The documents may come from teaching and research institutions in France or abroad, or from public or private research centers.
L'archive ouverte pluridisciplinaire HAL, est destinée au dépôt et à la diffusion de documents scientifiques de niveau recherche, publiés ou non, émanant des établissements d'enseignement et de recherche français ou étrangers, des laboratoires publics ou privés. 


\title{
Diode lasers for material processing
}

\author{
H.K. TÖNSHOFF, A. BERNDT, M. STÜRMER, D. GOLLA and J. SCHUMACHER
}

Laser Zentrum Hannover e.V., Germany

Diode lasers with output powers of several Watts have been commercially available for only a few years. This kind of beam source is increasingly interesting for industrial applications as well as for medical applications because of high reliability and low prices. Semiconductor laser systems can be applied particularly in fields in which conventional IR-lasers are too large. Two studies carried out by the Laser Zentrum Hannover e.V. showed potential application possibilities in the field of material treatment. A first study investigated joining and cutting with different plastics and metals using a 25 W-medicine-technical laser. During the tests it tumed out that with the output power of semiconductor systems used nowadays, material treatment is possible under industrial conditions. A second study dealt with the use of diode lasers as a pump source for Nd:YAG-lasers. After a high power diode-pumped Nd:YAG-laser had been developed firstly cutting and joining tests were carried out. Excellent results were achieved due to the very good beam quality of the diode-pumped system.

\section{Semiconductor lasers}

Shortly after the invention of the first laser, the laser operation of semiconductors was demonstated. Based upon the demand from measurement technology, laser diodes were developed with output powers of $<20 \mathrm{~mW}$. The life time of today's "low-power" laser diodes is in the range of several ten thousand hours, so that the construction elements are said to be extremely reliable and durable. They are commonly used for CD players, scanners and laser printers.

Recent developments in the field of high power diode lasers enable new applications in the field of laser material treatment. For diode-pumped Nd:YAG lasers, an overall efficiency which is more than 10 times higher in comparison to lamp-pumped lasers, can be achieved /1/. The excellent overlap between the diode laser output and the absorption spectrum of $\mathrm{Nd}$ yields these high efficiencies. Since diode-pumping introduces less technical noise, another advantage is low power fluctuations. Diode-pumped lasers with high stability and good beam quality are already comercially available for wafer-marking, trimming and link cutting of electronical components. Up to now, pulsed diodepumped slab lasers have reached an average output power of more than $1 \mathrm{~kW} / 2 /$.

A semiconductor laser is a diode, i.e. a pn-junction which is operated in forward bias. A population inversion is generated in the approx. $1 \mu \mathrm{m}$ thick active region by injecting electrons. By recombining electrons and defect-electrons ("holes") in the active region laser operation occurs above a characteristic threshold current density. Because of the high refractive index $(n=3,6)$ of the substrate material GaAs, a reflectivity of approx. $30 \%$ is already achieved at the passage to air; therefore the mirrors applied for conventional laser-resonators are not necessary. The wavelength of the laser radiation can be tuned within certain limits by varying the $\mathrm{Al}$-doping of the $\mathrm{Al}_{\mathrm{X}} \mathrm{Ga}_{1-\mathrm{X}} \mathrm{As-semiconductor}$, and so influencing the width of the band gap. By changing the operation current and the operation temperature, a fine tuning of the wavelength can be effected, which is in the near infrared at approx. $800 \mathrm{~nm}$. As the electric energy is directly changed into radiation energy a high modulation capability can be achieved which enables the use of laser diodes for communication systems.

Due to higher current density, laser diodes could, in the initial period, exclusively be used in pulsed operation, and only at temperatures of approx. $70 \mathrm{~K}$. Furthermore, the output power was limited to a few $\mathrm{mW}$. Only in the last few years has distinct progress in the semiconductor-component production allowed the production of high performance diodes with low threshold currents, operating at room temperature.

The efforts to enhance the operating current with a simultaneous decrease of the current density, and therefore an increase of the output power has been a red thread through the development history of semiconductors. By decreasing the operational current, the thermal load of the component could be decreased and therefore the component's life could be lengthened. The maximum output power is, however limited by the thermal destruction of the semiconductor crystal end-surface. At present, a massive step in increasing the output power is only possible by using the small dimensions of the resonator, integrating several laser diodes on a chip and collecting the radiation using micro optics. 


\title{
1. Direct use of diode lasers for material processing
}

\author{
Technical properties of a diode laser system
}

Semiconductors have many advantages for industrial use. The systems can be constructed compactly. The diode laser tested by the $\mathrm{LZH}$ has, incl. the cooling and power units, the dimensions of a typewriter. Due to the high operation efficiency of more than $30 \%$ only a power supply with normal mains connection is necessary. The power input is approx. $150 \mathrm{~W}$; the maximum achievable output in continuous wave operation is $25 \mathrm{~W}$ before fiber. Water cooling is not necessary since all components are air cooled. Except for the cooling fan, only electric components are used, so that no maintenance is necessary. The collecting- and the coupling-optics between the single diode lasers and the fiber optical wave guide is fully encapsulated; this ensures maintenance-free and adjustmentfree operation. The manufacturers offer step-index fibers of 400,600 and $1000 \mu \mathrm{m}$. In pulse operation frequencies from $1-10 \mathrm{~Hz}$ and pulse duration from $0,1-10 \mathrm{~s}$ are possible $/ 3 /$.

\section{Application examples}

As the wavelength of Nd:YAG with $1064 \mathrm{~nm}$ and of high-power diode lasers differ only about $250 \mathrm{~nm}$ and further optical fibers and transmissive glass optics can be used for beam guidance and beam forming, typical application fields of the Nd:YAG material processing were shown in the study. In the following paragraphs results are presented which were achieved with a simple experimental set-up, consisting of an optical fiber and a two-lens focusing optics, coated for $810 \mathrm{~nm}$ with a focal length of $f=50 \mathrm{~mm}$. The main goal of the study was not the process optimization for certain materials and material strengths, but to find the limits of the application possibilities with an estimation of the efficiency of this beam source type.

\section{Laser beam cutting}

The following criteria limit the cutting speed and the cutting quality:

- The beam intensity and the cutting gap-width defined by the aperture, fiber optics-diameter and focus diameter,

- the influence of the cutting quality by the thermal interaction, and

- the beam-material interaction (absorption and incoupling at $800 \mathrm{~nm}$ ).

Due to the high numeric aperture (N.A. $=0.5$ ) only a large focus diameter of nearly $1 \mathrm{~mm}$ could be realized with the existing simple optical set-up. This results in relatively wide cutting gap-widths, so that only thinner materials can be processed, e.g. foils.

Similar to cutting operations with all IR lasers, there is an influence of the edge zone due to thermal conductivity effects in connection with exothermic or pyrolytic decomposition. In pulse operation the thermal load of the work piece can be reduced, but at the same time the maximum cutting speed is limited by the minimum pulse overlap degree and is, therefore, distinctively under the theoretical limiting value given by the energy per unit length and the process operation ratio. For a system comparison between mounted optics and fiber optics, higher flexibility in fiber optics operation should be considered. Furthermore, investigations were carried out without co-axial process gas supply, which would result in an increase of the cutting speed because of effective lateral flow and an exothermal reaction of the material.

While detailed test results were carried out concerning the beam-material interaction for the known laser beam sources, even further research is still necessary for the wavelength of diode lasers; for technical as well as for medical applications. The different absorption behaviour in opposite to the $800 \mathrm{~nm}$ radiation according to the material composition is remarkable. 
The following table gives a view of the treated materials. Because of the developable set-up these results have to be seen as a first estimation. All tests have been completed with $\mathrm{N}_{2}$ atmosphere.

MATERIAL

net-shaped PE

iriodinized PE-foil

Capton ${ }^{R}$ foil

PP/PE-compound-flow

Polyamid-tissue

cotton-polyester-tissue

paper, wood-free

cardboard

mild steel

stainless stee

$\begin{array}{ll}\text { APPLICATION EXAMPLE } & \text { THICKNESS } \\ \text { shrink-tube } & 0,6 \mathrm{~mm} \\ \text { packing } & 0,06 \mathrm{~mm} \\ \text { contactfoil } & 0,05 \mathrm{~mm} \\ \text { hygiene-items } & 0,1 \mathrm{~mm} \\ \text { textiles-production } & 0,22 \mathrm{~mm} \\ \text { textiles-production } & 0,17 \mathrm{~mm} \\ \text { office and printing } & 80 \mathrm{~g} \\ \text { packing } & 0,7 \mathrm{~mm} \\ \text { diverse } & 0,05 \mathrm{~mm} \\ \text { diverse } & 0,025 \mathrm{~mm}\end{array}$

The achieved results demonstrate that material processing with a diode laser is already interesting for industrial applications.

\section{Laser soldering}

The main fields of applications are, up to now, fine soldering in the electronical industry and SMD technology. The adjustability of the laser radiation as well as the high local surface energy in connection with short heating periods are the expected advantages. Apart from slow processing speeds, there are still many other problems due to the complicated multi-directional beam guidance and the large number of single soldering points.

Soft soldering of copper foils and the contacting of electronical components on printed boards could be realized with output power of the diode laser of 10 and $25 \mathrm{~W}$ in less than one second. Similar to the Nd:YAG operation, the beam absorption in the PCB-material is here also considerably lower than in the solder. Therefore, thermal decomposition of the base material can virtually be excluded.

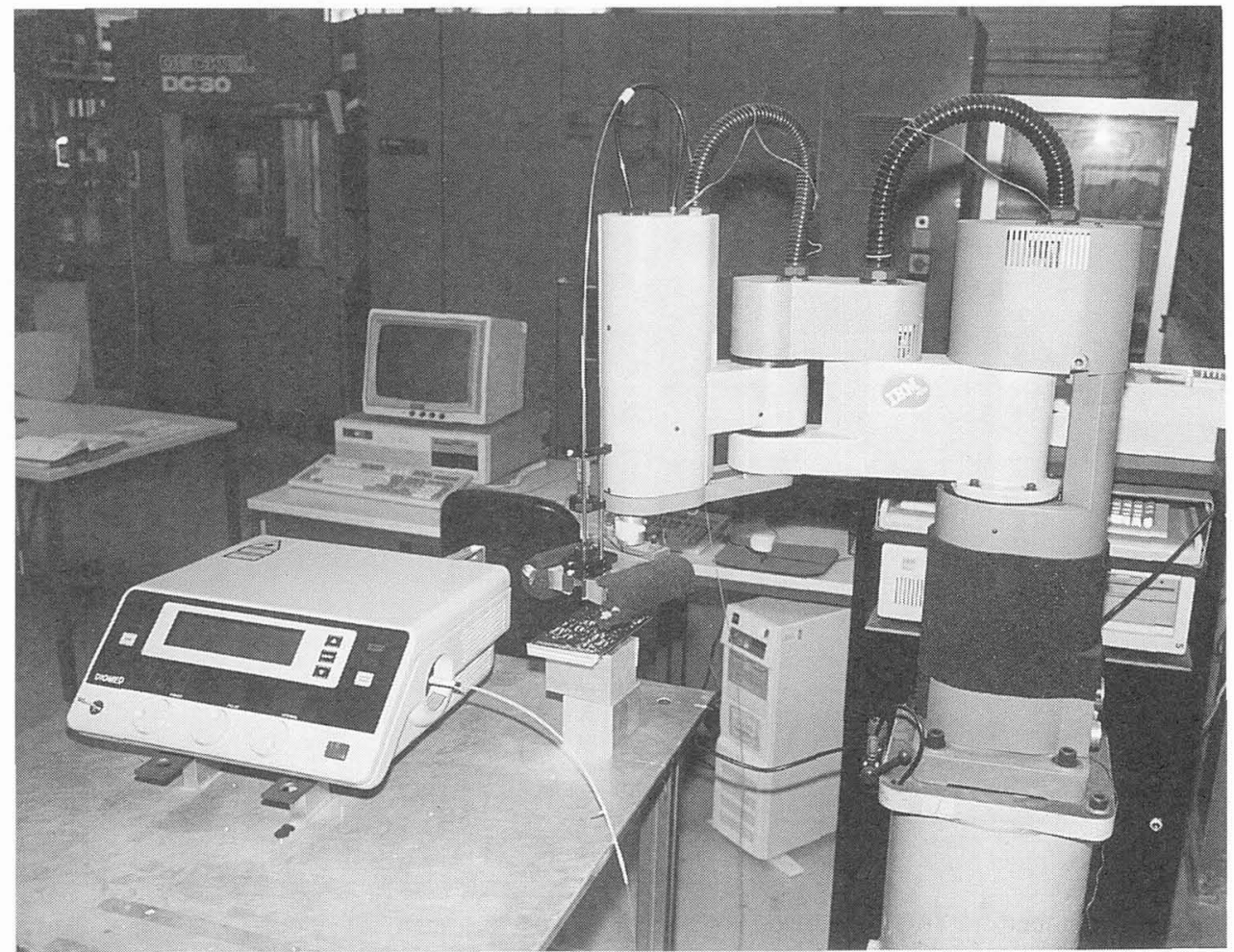

fig. 1: soldering of PCB; typical application of a diode laser system 


\section{Other fields of application}

Other applications for the diode laser are marking and laser lettering. Besides the imitation-proof marking, which is becoming more and more important because of product liability, especially the continuous expiration date marking of food and consumer goods without the disadvantages of stampand ink jet printers are conceivable. At present, "laser matrix inscribers" with 7 single adjustable, matrix-like arranged sealed- $\mathrm{CO}_{2}$-beam sources are offered. Diode arrays could bring improvements with regard to readability of the marking, but also with regard to lower system costs.

Simple operating systems, in contrast to the cutting operation, can be used quite well because of the low required guiding precision. From the technological point of view, ow output-semiconductor lasers should be preferred for wide-seam-foil welding of plastics. Welding metallic foils show, as expected, due to the low pulse frequency and energy densities, the tendency towards insufficient joining solidity and uncontrolled, wide-surface melting. If the minimum focus diameter is reduced by modifying the optical system, acceptable welding results can be expected.

\section{Diode-pumped Nd:YAG lasers in material processing}

\section{Diode-pumped solid state lasers}

Another project at the Laser Zentrum Hannover deals with the development of a diode-pumped high power Nd:YAG laser. The main advantages of diode-pumped solid state lasers are better beam quality and better efficiencies. A comparison between the absorption spectrum of Neodymium and an emission spectrum of an arc lamp shows that most of the emitted radiation could not be absorbed by the Nd. The thermal loading of the laser crystal causes strong thermal effects, e.g. thermal lensing. Diode lasers emit radiation with a wavelength of about $808 \mathrm{~nm}$. The wavelength can be shifted and controlled by current and temperature. For this reason the pump power can be matched to the strongest absorption maximum of Neodymium. Thus, optical to optical efficiencies of more than $30 \%$ can be achieved.

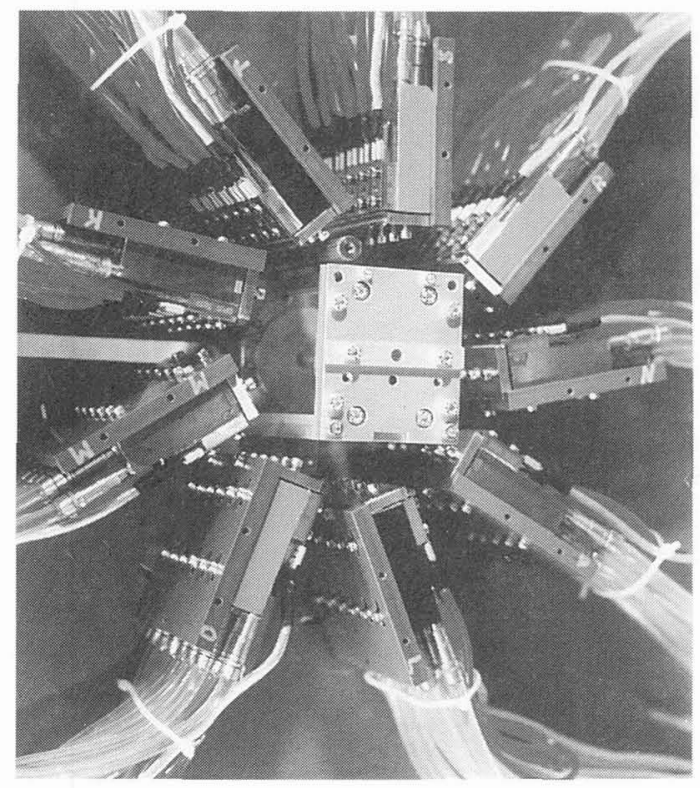

fig.2: diode-pumped Nd:YAG laser

The diode-pumped Nd:YAG-Laser used for the experiments has been developed at the Laser Zentrum Hannover. 54 diodes with an output power of about $500 \mathrm{~W}$ are focussed on the center axis of the laser rod, fig.2. Approximately $30 \%$ of the pump light is transmitted through the laser rod. 
Therefore reflectors, high reflecting at $808 \mathrm{~nm}$, are mounted around the rod in order to reflect back the transmitted diode laser radiation. This laser system generates an output power of $150 \mathrm{~W}$ with an optical slope efficiency of $32 \%$ and an overall efficiency of $6.5 \%$. The efficiency is more than 2 times higher in comparison to lamp-pumped Nd:YAG lasers. The beam quality at an output level of $120 \mathrm{~W}$ was determined to 6 mmmrad. In the near future, 1-2 mmmrad could be achieved by optimizing the system.

First experiments with this laser in material processing were carried out. The following table gives a view of the materials treated up to now:

$\begin{array}{lcccc}\text { cutting: } & & & & \\ \text { MATERLAL } & \text { THICKNESS } & \text { FEED } & \text { CUTTING-GAP-WIDTH } & \text { HEAT-EFFECTED-ZONE } \\ \text { mild steel } & 1,0 \mathrm{~mm} & 1,5 \mathrm{~m} / \mathrm{min} & 0,02 \mathrm{~mm} & 0,05 \mathrm{~mm} \\ \text { mild steel } & 0,6 \mathrm{~mm} & 1,8 \mathrm{~m} / \mathrm{min} & 0,33 \mathrm{~mm} & 0,13 \mathrm{~mm} \\ \text { brass } & 0,1 \mathrm{~mm} & 0,15 \mathrm{~m} / \mathrm{min} & 0,29 \mathrm{~mm} & 0,16 \mathrm{~mm} \\ \text { stainless steel } & 0,2 \mathrm{~mm} & 1,44 \mathrm{~m} / \mathrm{min} & 0,24 \mathrm{~mm} & 0,15 \mathrm{~mm} \\ \text { stainless steel } & 1,6 \mathrm{~mm} & 0,36 \mathrm{~m} / \mathrm{min} & 0,2 \mathrm{~mm} & 0,12 \mathrm{~mm} \\ \text { mild steel } & 0,8 \mathrm{~mm} & 2,4 \mathrm{~m} / \mathrm{min} & 0,29 \mathrm{~mm} & \text { no hez identificable }\end{array}$

All cutting tests have been completed with oxygen atmosphere.

welding:

stainless steel

stainless steel

mild steel

THICKNESS
$0,2 \mathrm{~mm}$
$1,6 \mathrm{~mm}$
$0,8 \mathrm{~mm}$

FEED
$1,2 \mathrm{~m} / \mathrm{min}$
$0,03 \mathrm{~m} / \mathrm{min}$
$0,12 \mathrm{~m} / \mathrm{min}$

The achieved results demonstrate that diode-pumped Nd:YAG-lasers became interesting for industrial material processing. In opposite to commercially available high-quality lamp-pumped systems with comparable beam-quality shows the potential for further improvements of diode-pumped system.

\section{Future perspectives}

Due to the steadily increasing number of variables as well as the efforis to produce according to "justin time"-criteria, the advantages of the laser will become more and more important in production engineering. The growing automatization, also in the field of laser technology, requires possibilities for process controlling and process adjustment. A principle-based advantage of the diode laser and the diode-pumped Nd:YAG laser are their modulation capability, which makes an on-line feedback of process-relevant signals to control the energy guiding parameters possible, as compared to the supply unit of conventional lasers, without thermal-based and capacitive-based idie times and performance variations.

It can be expected that the diode laser systems are going to be established in the performance range up to $100 \mathrm{~W}$ as independent, transportable low-cost tools for the 2- and 3-D operation. In fig. 1, this kind of facility conception is shown, consisting of a diode laser, fiber optics and SCARA robot. With increasing available performance, better efficiency and less investment costs, the diode laser can find, as the sealed-CO $\mathrm{CO}_{2}$-laser before, new application fields and markets for the laser technology.

The current development is to be estimated rapidly: the output power available per diode laser and diode-pumped Nd:YAG laser doubles nearly each year, while the price is halving within the same period. New developments are reported especially from medicine and production technology. However, in contrast to the optimistic predictions of kilowatt-diode lasers for the production technological usage, there are still massive disadvantages concerning investment costs, beam quality and reliability so that within this range of output power the conventional IR-laser sources will remain medium-term without competition.

\section{References}

I1/ D. Golla, A. Berndt, W. Schöne, I. Kröpke und H. Schmidt: "Mit Diodenlasern transversal angeregte Slab-Laser", Laser und Optoelektronik 25 (1), 1993 